\title{
A review of maternal and fetal outcome of induction of labour with Foley's catheter and extra amniotic saline infusion in women with previous caesarean delivery
}

\author{
Sunil Kumar, Nishtha A. Mahabalshetti*, Dinu Simon
}

Department of Obstetrics and Gynecology, SDM College of Medical Sciences and Hospital, Dharwad, Karnataka, India

Received: 01 August 2018

Revised: 05 August 2018

Accepted: 07 August 2018

\section{*Correspondence:}

Dr. Nishtha A. Mahabalshetti,

E-mail: drnishtha.shetti@gmail.com

Copyright: ( ) the author(s), publisher and licensee Medip Academy. This is an open-access article distributed under the terms of the Creative Commons Attribution Non-Commercial License, which permits unrestricted non-commercial use, distribution, and reproduction in any medium, provided the original work is properly cited.

\begin{abstract}
Background: Incidence of induction of labour has increased in the recent past due to increased screening facilities like ante partum fetal surveillance. Vaginal birth after caesarean section (VBAC) is one of the strategies developed to control the rising rate of caesarean sections. Intracervical Foley's catheter reduces the risk of uterus hyper tonicity and rupture in women with one caesarean section as it's placement induces the cervical repining without inducing any uterine contractions.

Methods: A prospective study of 35 women with one previous LCSs, term gestation and singleton pregnancy, were selected for trial of labour (TOL) considering inclusion and exclusion criteria.

Results: Out of 35 cases studied 21 cases (60\%) went for successful induction with Foleys and the remaining $40 \%$ underwent caesarean section. The mean time interval for Foley's expulsion was 6.74 in the success group and 10.04 in the failed group ( $\mathrm{p}$ value $<0.05$ ). In 4 cases there were meconium stained liquor, and they underwent emergency LSCS. One case $(2.8 \%)$ had scar rupture which also underwent caesarean section.

Conclusions: This study shows that the Foley catheter is an effective method of cervical ripening with additional benefit of low cost, reversibility, easy availability and lack of need for special storage. This method confers significant improvement in Bishop Score and vaginal delivery was achieved in majority of patients.
\end{abstract}

Keywords: Extra amniotic saline infusion, Foley's catheter, Induction of labour, Previous LSCS

\section{INTRODUCTION}

Vaginal birth after caesarean section (VBAC) is a trial of vaginal delivery in selected cases of a previous CS. Induction of labour defined as stimulation of regular uterine contractions before the spontaneous onset of labour with or without rupture of membrane after 28 weeks of gestational age using mechanical or pharmacological methods in order to generate progressive cervical dilations and subsequent delivery. ${ }^{1}$
In 1916, Cragin popularized the dictum, "once a caesarean section, always a caesarean section". ${ }^{1}$ The dictum now is "once a caesarean section, always an institutional delivery in a well-equipped hospital.

The Cochrane review of mechanical methods of IOL suggest that mechanical methods have equivalent clinical effectiveness to prostaglandins with no overall significant difference in caesarean section rates, vaginal delivery within 24 hours of inductions, or need for oxytocins and 
lower rates of hyper stimulations with fetal heart rate abnormalities. $^{2}$

The use of intracervical Foley's catheter reduces the risk of uterus hyper tonicity and rupture in women with one caesarean section as the intracervical placement of Foleys catheter induces the cervical repining without inducing any uterine contractions. ${ }^{3,4}$

Misoprostol has been proposed an effective and economical agent for cervical ripening for induction but the incidence of rupture was found to be the highest among several studies. ${ }^{5}$

The aim of this study is to know the maternal and fetal outcome of induction of labour with Foley catheter and extra amniotic saline infusion in women with previous caesarean delivery.

\section{METHODS}

The subject of the study was selected from the patients who had been admitted to labour ward Sri Dharmastala Manjunatheshwara College of Medical Sciences and Hospital, Dharwad, from November 2014 to November 2015 as a time bound study.

\section{Inclusion criteria}

- Women with one previous lower segment caesarean section

- Singleton pregnancy

- Cephalic presentation

- $\quad>39$ weeks of gestation.

\section{Exclusion criteria}

- Two or more caesarean sections

- Teenage pregnancy

- Previous uterine surgery like myomectomy

- $\quad$ Estimated fetal weight $>4 \mathrm{~kg}$

- Inter delivery interval $<18$ months

- Previous classical caesarean section

- Contracted pelvis

- PROM

- Medical or obstetrical complication (placenta previa, twin gestation, polyhydraminous).

A prospective study of women with term gestation with singleton pregnancy, who underwent one caesarean section after considering inclusion and exclusion criteria, were included in this study.

A total of 35 cases with previous one caesarean delivery were assessed and selected for trial of labour (TOL). Patient explained about trial of labour (TOL) with Foley catheter, extra amniotic saline infusion (EASI) and its consequences and advantages. Those who were willing for trial of labour (TOL), singleton live pregnancy $>39$ weeks with cephalic presentation with Bishop score <6 were included in the study. Bishop score reassessed at the time of expulsion of the catheter or at the onset of effective uterine contractions or after a period of 18 hours of Foley insertion. The technique of Foley catheter was explained to the patient and informed consent taken. In lithotomy position, cleansing of vulva and vagina carried out with antiseptics. Cervix visualized with the help of Cusco's speculum. While holding the Foley catheter No.18 with a long artery forceps near its tip, it is passed into the cervical canal extra-aminiotically under vision and the tip advanced up to $5 \mathrm{~cm}$ to ensure that the balloon is within the uterine cavity. The balloon inflated with $30 \mathrm{cc}$ of sterile water. The catheter pulled down to bring the balloon into the cervical canal and taped around the thigh under minimal strain. A 20 minute fetal heart trace was obtained before starting the procedure and repeated if indicated. The feto-maternal monitoring is carried out hourly and half hourly in active labour. Bishop score reassessed at the time of expulsion of the catheter or after at the onset of effective uterine contractions or after a period of 14 hours of insertion. Amniotomy was done and syntocinon infusion containing 2.5 units in $500 \mathrm{ml}$ of ringer lactate started with 30 minutes increment. The feto maternal monitoring performed using CTG. The procedure was discontinued in case of antepartum haemorrhage, infection, fetal distress and tonically contracted uterus. Demographic data, details of obstetric history, intrapartum events, and postpartum events were recorded.

Neonatal data was collected till the hospital stay and additional details was collected regarding clinical course of all neonates admitted to neonatal ICU.

\section{Statistical analysis}

Data entry and analysis was carried out using SPSS version 16(2006, SPSS Inc., Chicago, IL, USA).

\section{Descriptive statistics}

Quantitative data are expressed to measure the central tendency of data and diversion around the mean, mean(x)and standard deviation (SD). Qualitative data are expressed in number and percentage.

\section{Analytic statistics}

T test was used for comparison of two groups of normally distributed variables. All these tests were used as tests of significance at: $\mathrm{P}$ value $>0.05$ was considered statistically not significant. $\mathrm{P}$ value $\leq 0.05$ was considered statistically significant. $\mathrm{P}$ value $\leq 0.001$ was considered statistically highly significant.

\section{RESULTS}

Out of 35 patients, 32 were in the age group 20- 30 with a mean age of 25.03 and SD 2.97. 21 patients underwent 
successful induction with Foleys catheter (60\%). Success and failure were almost similar in the age group 20-30 though failure was slightly more in the age group above 30 (Statically not significant).

Table 1: Comparison of outcome (success and failure) with age groups.

\begin{tabular}{|lllllll|}
\hline Age groups & Total & $\%$ & Success & $\%$ & Failed & $\%$ \\
\hline $20-25 y r s$ & 16 & 45.71 & 10 & 62.5 & 6 & 37.50 \\
\hline $26-30 \mathrm{yrs}$ & 16 & 45.71 & 10 & 62.5 & 6 & 37.50 \\
\hline$\geq 31 \mathrm{yrs}$ & 3 & 8.57 & 1 & 33.33 & 2 & 66.67 \\
\hline Chi-square=0.9722; $\mathrm{P}=0.6151$ & & & & & \\
\hline Total & 21 & 60.00 & 14 & 40.00 & 35 & 100.00 \\
\hline Mean age & 25.50 & & 24.71 & & 25.03 & \\
\hline SD age & 3.78 & & 2.33 & & 2.97 & \\
\hline
\end{tabular}

Fetal distress was the most common indication for the LSCS in the previous pregnancy $(42.86 \%)$.

For the previous delivery Elective LSCS was done in $5 / 35$ of the cases. Out of that 4 cases were breech and one was big baby. Out of the 30 cases of emergency LSCS majority were because of fetal distress (15/30). The other indications for emergency LSCS were PROM, failed induction, oligohydramnios, post term, post datism and non severe preeclampsia in decreasing order.

Table 2: Association between previous deliveries with status of Indication for previous LSCS.

\begin{tabular}{|lllll|l|l|}
\hline Indication for previous LSCS & Emergency LSCS & $\%$ & Elective LSCS & Total & \% \\
\hline Big baby & 0 & 0.00 & 1 & 100.00 & 1 & 2.86 \\
\hline Breech & 0 & 0.00 & 4 & 100.00 & 4 & 11.43 \\
\hline Failed induction & 3 & 100.00 & 0 & 0.00 & 3 & 8.57 \\
\hline Fetal distress & 15 & 100.00 & 0 & 0.00 & 15 & 42.86 \\
\hline Non-severe preeclampsia & 1 & 100.00 & 0 & 0.00 & 1 & 2.86 \\
\hline Oligohydramnios & 3 & 100.00 & 0 & 0.00 & 3 & 8.57 \\
\hline Post datism & 1 & 100.00 & 0 & 0.00 & 1 & 2.86 \\
\hline Post term & 2 & 100.00 & 0 & 0.00 & 2 & 5.71 \\
\hline Prom & 5 & 100.00 & 0 & 0.00 & 5 & 14.29 \\
\hline Total & 30 & 85.71 & 5 & 14.29 & 35 & 100.00 \\
\hline
\end{tabular}

Table 3: Comparison of outcome (success and failure) with indication for previous LSCS.

\begin{tabular}{|lllllll|}
\hline Indication for previous LSCS & Success & $\%$ & Failed & $\%$ & Total & $\%$ \\
\hline Big baby & 0 & 0.00 & 1 & 100.00 & 1 & 2.86 \\
\hline Breech & 4 & 100.00 & 0 & 0.00 & 4 & 11.43 \\
\hline Failed induction & 1 & 33.33 & 2 & 66.67 & 3 & 8.57 \\
\hline Fetal distress & 8 & 53.33 & 7 & 46.67 & 15 & 42.86 \\
\hline Non-severe preeclampsia & 0 & 0.00 & 1 & 100.00 & 1 & 2.86 \\
\hline Oligohydramnios & 1 & 33.33 & 2 & 66.67 & 3 & 8.57 \\
\hline Post datism & 1 & 100.00 & 0 & 0.00 & 1 & 2.86 \\
\hline Post term & 1 & 50.00 & 1 & 50.00 & 2 & 5.71 \\
\hline Prom & 5 & 100.00 & 0 & 0.00 & 5 & 14.29 \\
\hline Total & 21 & 60.00 & 14 & 40.00 & 35 & 100.00 \\
\hline
\end{tabular}

For the previous LSCS, Emergency LSCS was done in 30 of the 35 patients $(85.71 \%)$. Fetal distress was the most common indication for previous LSCS $(15 / 35,42.85 \%)$, 8 of those cases underwent successful induction with
Foleys catheter. All the cases of breech (4) went for successful induction with Foleys catheter. All the PROM cases (5) also went for successful induction. Out of the 21 successful induction cases, instrumental deliveries 
happened in $6(28.6 \%)$ of them in order to cut short the second stage of labor. In rest of the 15 cases of successful induction there was no need for that as the second stage was already short. There was no statistically significant association of the outcome with the mean birthweight.
There was no statistically association with the mean gestational age in the success and failed groups. The mean GA in the success group was 39.90wks and $39.92 \mathrm{wks}$ in the failure group.

Table 4: Comparison of outcome (success and failure) with gestational age, birthweight and time interval for expulsion of Foley's.

\begin{tabular}{|llllllll|}
\hline & Total & Gestational age & Birth weight & \multicolumn{3}{c|}{ Time interval for Foley's expulsion } \\
\hline Outcome & $\mathbf{n}$ & Mean GA & SD & Mean Bwt & SD & Mean Hrs & SD \\
\hline Success & 21 & 39.90 & 0.30 & 3.1 & 0.2 & 6.74 & 2.48 \\
\hline Failed & 14 & 39.92 & 0.22 & 3.2 & 0.23 & 10.04 & 4.09 \\
\hline Total & 35 & 39.91 & 0.27 & & 0.22 & 8.06 & 3.56 \\
\hline t-value & -0.2807 & & & 0.8334 & & -2.9774 & $0.0054^{*}$ \\
\hline p-value & 0.7807 & & 0.4106 & & & \\
\hline
\end{tabular}

Table 5: Comparison of pre-test and post-test BISHOP scores in total, success and failure outcome by paired t-test.

\begin{tabular}{|c|c|c|c|c|c|c|c|c|}
\hline Samples & Time & Mean & SD & Mean Diff. & SD Diff. & $\%$ of change & Paired t & p-value \\
\hline Total & Pre-test & 3.26 & 0.89 & \multirow{2}{*}{4.51} & \multirow{2}{*}{1.46} & \multirow{2}{*}{138.60} & \multirow{2}{*}{18.2586} & \multirow{2}{*}{$0.0001 *$} \\
\hline BISHOP & Post-test & 7.77 & 2.09 & & & & & \\
\hline Success & Pre-test & 3.71 & 0.72 & \multirow{2}{*}{5.38} & \multirow{2}{*}{0.59} & \multirow{2}{*}{144.87} & \multirow{2}{*}{41.8232} & \multirow{2}{*}{$0.0001 *$} \\
\hline BISHOP & Post-test & 9.10 & 0.70 & & & & & \\
\hline Failed & Pre-test & 2.57 & 0.65 & 3.21 & 1.42 & 125.00 & 8.4464 & $0.0001 *$ \\
\hline
\end{tabular}

The mean time interval for Foleys expulsion was lower in the success group (6.74 hrs.) than the failure group (10.04 hrs.) and this was found to be statically significant $(<0.05)$.

Table 6: Indication for current LSCS.

\begin{tabular}{|lll|}
\hline Indication for LSCS & $\begin{array}{l}\text { No of } \\
\text { respondents }\end{array}$ & $\begin{array}{l}\% \text { of } \\
\text { respondents }\end{array}$ \\
\hline $\begin{array}{l}\text { Failed Induction } \\
\text { Fetal distress } \\
\text { (meconium) }\end{array}$ & 9 & 64.29 \\
\hline Scar rupture & 4 & 28.57 \\
\hline Total & 1 & 7.14 \\
\hline
\end{tabular}

The mean Bishops score was calculated before and after induction in the success, failure and total group. In the total group pre- test mean was 3.26 while the post -test mean was 7.77. Similarly, in the success group, the pre test mean was 3.71 and the post test mean was 9.10 .

In the failure group the pre test mean 2.57 and the post test mean was 5.79. There was a statistically significant relation in these observations $(p<0.05)$ suggesting the efficacy of Foleys as a good induction method. Out of the total 35 cases kept for induction, meconium stained liquor was seen in $4(11.43 \%)$ of the cases. These cases went for emergency LSCS and constituted $28.6 \%(4 / 14)$ of the failed group
The 1 and 5minute APGAR readings were slightly higher in the success group than the failure group (8.14 and 8.00). There were no ICU admissions in the failure group or the success group.

Out of the total 35 cases studied $21(60 \%)$ went for successful vaginal delivery after induction with Foleys catheter and EASI. The rest $40 \%$ underwent LSCS.

Failed induction was the most common cause for repeat LSCS $(64.29 \%)$. The other indications were fetal distress (meconium $-28.57 \%$ ) and scar rupture (7.14\%).

\section{DISCUSSION}

Labour-defined as the initiation and perpetuation of uterine contractions with the goal of producing progressive cervical effacement and dilation. Induction implies stimulation of contractions before the spontaneous onset of labour, with or without ruptured membrane. $^{7}$

\section{Extra amniotic saline infusion (EASI)}

The use of an extra-amniotic catheter balloon inflated above the internal os and additional measure may include applying traction on catheter or infusion of normal saline via catheter port into extra-amniotic space, has been advocated. ${ }^{8}$ 
A systemic review and meta-analysis of 30 trials found that Foleys catheter induction alone compared with prostaglandin resulted in higher infection rates unless saline was infused (Heinemann). ${ }^{8}$

Cromi and colleagues compared a double triple Foleys catheter and the dinoprostone vaginal insert. They found higher rates of delivery within 24 hours with mechanical technique, but no difference in the caesarean delivery rates. $^{9}$

The PROBAAT trials, in which cervical ripening with a Foleys catheter was compared with a vaginal dinoprostonegel, dinoprostone vaginal inserts and vaginal misoprostol, reported similar outcomes between the mechanical technique and prostaglandin agents. ${ }^{10}$

\section{Induction of labour in previous LSCS}

TOL must be conducted in a hospital where emergency caesarean section can be performed, and the baby delivered within 30 minutes. The patient must be closely observed for signs of scar dehiscence and fetal distress. Successful vaginal delivery has been reported in $50-75 \%$ of women selected carefully for induction of labour. ${ }^{11,12}$ There is two to three fold increase risk of uterine rupture, and about 1.5 fold increased risk of caesarean section in induced labours compared to spontaneous labour. ${ }^{13}$

A total of 35 cases with previous one caesarean delivery were assessed, selected for trial of labour (TOL) and induced with Foleys and EASI. The results were analyzed with respect to maternal age, gestational age, previous delivery, pre and post induction bishop scores, current delivery mode, Foleys expulsion time, fetal outcome and maternal complications.

\section{Induction of labour in previous LSCS with Foley's}

It acts by physically dilating the cervix, disrupting collagen and causing localized inflammation, increasing prostaglandin and oxytocin secretion. The advantage with the Foley catheter is it's low cost, reversibility, lack of systemic or other serious side effects and uterine hyper stimulation and rupture. It reduces the induction to delivery interval.

A total of 35 cases with previous one caesarean delivery were assessed, selected for trial of labour (TOL) and induced with Foleys and EASI. The results were analyzed with respect to maternal age, gestational age, previous delivery, pre and post induction bishop scores, current delivery mode, Foleys expulsion time, fetal outcome and maternal complications.

\section{Demographic profile}

Out of 35 patients, 32 were in the age group 20- 30 with a mean age of 25.03 and SD $2.97(25.03 \pm 2.97)$. The rests were above 30 years of age.
Table 7: Comparison of maternal age with other studies.

\begin{tabular}{|ll|}
\hline Study done by & Maternal age \\
\hline Guinn et al & \\
\hline Goldman et $^{17}$ & $23.0 \pm 5.7$ \\
\hline Karjane et $^{18}{ }^{16}$ & $25.1 \pm 7.0$ \\
\hline Present study & 25.6 \\
\hline
\end{tabular}

Present study was comparable to studies of Goldman et al and Guinn et al. Out of the total 35 patients studied 21 underwent successful induction with Foleys catheter $(60 \%)$. Success and failure were almost similar in the age group 20-30 though failure was slightly more in the age group above 30 (Statically not significant).

\section{Gestational age and outcome}

There was no statistically association with the mean gestational age in the success and failed groups. The mean GA in the success group was 39.90 and 39.92 in the failure group. The mean gestational age was comparable to the studies by Guinn et al and Goldman et al. ${ }^{17,18}$

Table 8: Comparison of gestational age with other studies.

\begin{tabular}{|ll|}
\hline Study done by & Gestational age \\
\hline Guinn et $\mathrm{al}^{17}$ & $39.4 \pm 2.1$ \\
\hline Karjane et al $^{16}$ & 39.6 \\
\hline Present study & $39.90 \quad 0.30$ \\
\hline
\end{tabular}

\section{Status of past delivery and outcome}

$80 \%$ of the elective CS and $56.67 \%$ of emergency CS went for successful induction with Foleys catheter. There was no statistical association of success or failure with the status of the past delivery

\section{Indication for previous LSCS}

Fetal distress was the most common indication for the LSCS in the previous pregnancy $(42.86 \%)$. For the previous delivery, Elective LSCS was done in $5 / 35$ of the cases. Out of that 4 cases were breech and one was big baby. Out of the 30 cases of emergency LSCS majority were because of fetal distress (15/30).

Out of the 21 successful induction cases, instrumental deliveries happened in $6(28.6 \%)$ of them in order to cut short the second stage of labor. In rest of the 15 cases of successful induction there was no need for that as the second stage was already short.

\section{Bishops score and outcome}

The mean Bishops score was calculated before and after induction in the success, failure and total group. In the total group pre test mean was 3.26 while the post test 
mean was 7.77. Similarly, in the success group, the pre test mean was 3.71 and the post test mean was 9.10. In the failure group the pre test mean 2.57 and the post test mean was 5.79. There was a statistically significant relation in these observations $(p<0.05)$ suggesting the efficacy of Foleys as a good induction method. Pre induction Bishops score: In the present study, the pre and post -induction Bishops score was 3.26 and 7.77 which was comparable to Goldman et al, with pre and post induction score being 3.5 and 8.16 respectively. The mean time interval for Foleys expulsion was lower in the success group (6.74 hrs.) than the failure group (10.04 $\mathrm{hrs}$.) and this was found to be statically significant ( $p$ $<0.05)$. There was no statistically significant association of the outcome with the mean birth weight. The mean birth -weight in the present study was comparable to Kajrane et al and Jameela et al with mean birth weight of 3.085 and 2.77 respectively.

\section{Current LSCS}

Out of the total 35 cases studied 21 (60\%) went for successful vaginal delivery after induction with Foleys catheter and EASI. The rest $40 \%$ underwent LSCS. Failed induction was the most common cause for repeat LSCS (64.29\%). The other indications were fetal distress (meconium-28.57\%) and scar rupture (7.14\%). Comparison with other studies.

\section{Table 9: Comparison of rate of vaginal deliveries and LSCS.}

\begin{tabular}{|lll|}
\hline Study by & \multicolumn{2}{l|}{ Foleys with EASI } \\
\hline \multirow{2}{*}{ Goldman et al ${ }^{18}$} & Vaginal & $38.5 \%$ \\
\cline { 2 - 3 } & LSCS & $61.5 \%$ \\
\hline \multirow{2}{*}{ Reuben et al ${ }^{19}$} & Vaginal & $73.3 \%$ \\
\cline { 2 - 3 } & LSCS & $26.7 \%$ \\
\hline \multirow{2}{*}{ Present study } & Vaginal & $60 \%$ \\
\cline { 2 - 3 } & LSCS & $40 \%$ \\
\hline
\end{tabular}

Table 10: Comparison of indication for LSCS.

\begin{tabular}{|c|c|c|}
\hline Study by & Indication & EASI \\
\hline \multirow{3}{*}{ Guinn et al ${ }^{17}$} & Failed induction & $9.6 \%$ \\
\hline & Failure to progress & $61.1 \%$ \\
\hline & Fetal distress & $29.3 \%$ \\
\hline \multirow{3}{*}{$\begin{array}{l}\text { Reuben } \\
\text { et } \mathrm{al}^{19}\end{array}$} & Failed induction & $20.46 \%$ \\
\hline & Failure to progress & $46.54 \%$ \\
\hline & Fetal distress & $23 \%$ \\
\hline \multirow{3}{*}{ Present study } & Failed induction & $64.29 \%$ \\
\hline & Fetal distress & $28.57 \%$ \\
\hline & Scar rupture & $7.14 \%$ \\
\hline
\end{tabular}

\section{Fetal outcome}

\section{Meconium}

Out of the total 35 cases kept for induction, meconium stained liquor was seen in $4(11.43 \%)$ of the cases which was comparable with Jameela et al and Guin et al (8\% and $13.71 \%$ respectively). These cases went for emergency LSCS and constituted $28.6 \%$ (4/14) of the failed group.

\section{Maternal outcome}

Out of the 35 cases, one case went in for scar rupture $(2.8 \%)$. Other than that, there was no incidence of PPH and puerperal infection.

Bujold E et al studied the rate of uterine rupture in patient with a previous caesarean delivery is related to labour induction and or cervical ripening using transcervical Foley catheter and concluded that labour concluded that labour induction using a transcervical Foley catheter was not associated with an increased risk of uterine rupture.

Kausar $\mathrm{S}$ et al studied the effectiveness of hydrostatic membrane sweeping with intracervical Foley catheter in pre induction cervical ripening, and concluded that Foley catheter is effective methods of cervical ripening however the later was more effective for improvement in Bishop score and in achieving vaginal delivery. ${ }^{14}$

Rezk M et al a prospective study, on efficacy, safety, acceptability and outcome of labour and concluded that intracervical Foley catheter is effective, safe and acceptable for labour induction in women with previous one lower segment caesarean section. ${ }^{15}$

Karjane NW et al did a retrospective study, on transcervical Foley bulb with and without extra aminiotic saline infusion for induction of labour in patient with an unfavourable cervix and concluded that induction of labour by using Foley with extra amniotic saline infusion results in shorter induction to vaginal delivery time than Foley alone, without affecting caesarean delivery rate. ${ }^{16}$

According Lewis $\mathrm{S}$ et al study the 37 women in this study all had a Bishop's score of less than 6. Successful cervical ripening (defined as a Bishop score 5) was attained in $2.3 \%$ of the women. More than two-thirds (78.6\%) of those women went on to have a successful vaginal birth, while $21.4 \%$ required a repeat caesarean delivery. No significant adverse events were reported for either the women or their babies.

\section{CONCLUSION}

Inducing labour in patient with previous caesarean is highly challenging to obstetrician. Cervical Ripening with Foley catheter with or without extra amniotic saline infusion (EASI) is been studied and shown to have good results with minimal major side effects.

EASI is one such mechanical method which commonly used in case of previous caesarean section. It is an effective in achieving vaginal delivery. It has got other advantages like, higher post induction Bishop score, less 
duration of augmentation, shorter induction delivery interval, less painful, less chance failure of induction with good maternal fetal outcome.

Hence intracervical Foley catheter is effective and acceptable for labour induction in women with previous one lower segment caesarean section.

Funding: No funding sources

Conflict of interest: None declared

Ethical approval: Not required

\section{REFERENCES}

1. Mishra R. Management of labour. Renu Mishra. Ian Donald ${ }^{\text {ee }} \mathrm{s}$, Practical obstetric problems. $7^{\text {th }}$ ed. BI publications: New Delhi; 2014:584.

2. Jozwiak M, Rengerink KO, Ten Eikelder ML, van Pampus MG, Dijksterhuis MG, de Graaf IM et al. Foley catheter or prostaglandin E2 inserts for induction of labour at term: an open-label randomized controlled trial (PROBAAT-P trial) and systematic review of literature. Eur J Obstet Gynecol Reprod Biol. 2013 Sep;170(1):137-45.

3. Ledingham MA, Denison FC, Kelly RW, Young A, Norman JE. Nitric oxide donors stimulate prostaglandin $\mathrm{F} 2 \alpha$ and inhibit thromboxane B2 production in the human cervix during the first trimester of pregnancy. Molecular Human Reproduction. 1999 Oct;5(10):973-82.

4. Shi L, Shi SQ, Saade GR, Chwalisz K, Garfield RE. Studies of cervical ripening in pregnant rats: effects of various treatments. Molecular Human Reprod. 2000 Apr;6(4):382-9.

5. American College of Obstetricians and Gynecologists Committee on Obstetric Practice. ACOG Committee Opinion No.342: induction of labour for vaginal birth after caesarean delivery. Obstet Gynecol. 2006 Aug;108(2):465-8.

6. Gary CF. Willams Obstetrics. $24^{\text {th }}$ ed. New York: McGraw Hill; 2014:523.

7. Sherman DJ, Frenkel E, Pansky M, Caspi E, Bukovsky I, Langer R. Balloon cervical ripening with extra-amniotic infusion of saline or prostaglandin E2: a double-blind, randomized controlled study. Obstet Gynecol. 2001 Mar;97(3):375-80.

8. Heinemann J, Gillen G, Sanchez-Ramos L, Kaunitz AM. Do mechanical methods of cervical ripening increase infectious morbidity? A systematic review. Am J Obstet Gynecol. 2008 Aug 1;199(2):177-88.

9. Cromi A, Ghezzi F, Uccella S, Agosti M, Serati M, Marchitelli $G$ et al. A randomized trial of preinduction cervical ripening: dinoprostone vaginal nsert versus double-balloon catheter. Am J Obstet Gynecol. 2012 Aug;207(2):125-e1.

10. Jozwiak M, Rengerink KO, Benthem M, van Beek E, Dijksterhuis MG, de Graaf IM, et al. Foley catheter versus vaginal prostaglandin E2 gel for induction of labour at term (PROBAAT trial): an open-label, randomised controlled trial. Lancet. 2011 Dec 17;378(9809):2095-103.

11. Agnew G, Turner MJ. Vaginal prostaglandin gel to induce labour in women with one previous caesarean section. J Obstetric Gynaecol. 2009 Jan;29(3):20911.

12. Nooh A. Is it worth inducing labour in women with a previous caesarean delivery. J Obstet Gynaecol. 2012 Feb;32(2):141-4.

13. Royal College of Obstetricians and Gynaecologists. Birth after previous caesarean birth. Green-top guideline. 2007(45).

14. Kausar, S, Ali R. A comparison of effectiveness of hydrostatic membrane sweeping with intracervical Foley catheter ballooning alone in pre induction cervical ripening. APMC. 2012 Jan;6(1):51-5.

15. Rezk M, Sanad Z, Dawood R, Masood A, Emarh M, Al Halaby A. intracervical foley catheter versus vaginal isosorbid mononitrate for induction of labor in women with previous one cesarean section. J Clin Gynecol Obstet. 2014 May;3(2):55-61.

16. Karjane NW, Brock EL, Walsh SW. Induction of labor using a foley balloon, with and without extraamniotic saline infusion. Obstet Gynecol. 2006 Feb;107(2, Part 1):234-9.

17. Guinn DA, Goepfert AR, Christine M, Owen J, Hauth JC. Extra-amniotic saline, laminaria, or prostaglandin E 2 gel for labor induction with unfavorable cervix: a randomized controlled trial. Obstet Gynecol. 2000 Jul 31;96(1):106-12.

18. Goldman JB, Wigton TR. A randomized comparison of extra amniotic saline infusion and intra cervical dinoprostone gel for cervical ripening. Obstet Gynecol. 1999;93:271-4.

19. Rouben D, Arias F. A randomized trial of extraamnioticsaline infusion plus intracervical Foley catheter balloon versus prostaglandin E2 vaginal gel for ripening the cervix and inducing labor in patient with unfavorable cervixes. Obstet Gynecol.1993;82:290-4.

Cite this article as: Kumar S, Mahabalshetti NA, Simon D. A review of maternal and fetal outcome of induction of labour with Foley's catheter and extra amniotic saline infusion in women with previous caesarean delivery. Int J Reprod Contracept Obstet Gynecol 2018;7:3551-7. 